\title{
Status and Prospects of Municipal Solid Waste Treatment in China
}

\author{
X.S. DOU, P. JING, Z.F. WANG \& H.M. YUAN \\ School of Public Administration, Southwest Jiaotong University, Chengdu 610031, P.R. China
}

\begin{abstract}
With urban development and the increasing improvement of people's living standards, amount of municipal solid waste generated in the city are constantly increasing, too. Municipal solid waste contains large amounts of harmful substances, which will cause serious influence on the urban environment and people's health. Therefore, it is necessary to conduct an effective treatment for municipal solid waste. This research demonstrates that, at the present stage, most of municipal solid wastes are processed by way of the landfill and only a small part is processed by composting and incineration method, resulting in a low level in resource recovery and harmless treatment. The reasons causing the results are such factors as technology, system, market, policy and so forth. Therefore, it is necessary through technology, system and management innovation to solve the problems.
\end{abstract}

KEYWORD: Municipal solid waste; Landfill treatment; Environmental hazards; Resource recovery and harmless treatment

\section{INTRODUCTION}

With urbanization development and the increasing improvement of people's living standards, municipal solid waste in the city continues to grow. The generation of large numbers of municipal solid waste not only affects urban environment, but also causes serious impact on people's health. How to effectively treat municipal solid waste has been one of the important problems solved by city (Tian et al. 2013).

In theory, treatment technologies of municipal solid waste have landfill, high-temperature sterilization or microbiologic fermentation into animal feed, aerobic composting, anaerobic digestion into biogas and fertilizer, pyrolysis conversion into organic matter, and incineration and power generation (Dou 2015). However, due to technical and cost constraints, most of the cities in China at the present stage adopt the landfill and only a few cities use composting technology (Wei et al. 2000). In recent years, incineration and power generation technology has begun to be popularized and applied, but on the whole it is not universal (Zhang et al. 2010).

The fundamental problem of municipal solid waste treatment is how to comprehensively realize environmental benefits, social benefits and economic benefits in waste treatment, as it is the basic requirement for municipal solid waste treatment and sustainable development (Dou 2013). However, how to do it, there are many problems in practice, and it is one of the core problems that have to be solved in China's municipal solid waste treatment in the future. This paper mainly analyses the related problems combined with the present situation of China's municipal solid waste treatment, and will make a prospect for the further development in the future.

\section{PRESENT SITUATION AND PROBLEMS}

\subsection{Selection and application of treatment technologies}

As municipal solid waste contains large amounts of organic matter (especially in living waste) and heavy metals (especially in e-waste), so if not to make timely scientific treatment, it will cause serious pollution to the urban environment (Zhou et al. 2014). However, most of the municipal solid wastes in China's cities at the present stage are treated by way of the landfill, and only a small part is processed through composting and incineration.

As shown in Table 1, harmless treatment rate of municipal solid waste in 2004 is only $52.1 \%$, but gradually rising to $84.8 \%$ in 2012 . In the treatment method, in 2004 the proportion of landfill accounted for 85.17 and the proportion of composting was $9.25 \%$, but the proportion of incineration was only $5.55 \%$. However, since 2004 the proportion of the landfill and composting has taken a decline, while 
the proportion of incineration has risen from $5.55 \%$ in 2004 to $24.74 \%$ in 2012.

Table 1 Ratio of different treatment technologies (\%)

\begin{tabular}{|c|c|c|c|c|}
\hline Year & $\begin{array}{c}\text { Harmless } \\
\text { treatment }\end{array}$ & Landfill & $\begin{array}{c}\text { Aerobic } \\
\text { composting }\end{array}$ & Incineration \\
\hline 2004 & 52.1 & 85.17 & 9.25 & 5.55 \\
\hline 2005 & 51.7 & 85.17 & 4.29 & 9.83 \\
\hline 2006 & 52.2 & 81.40 & 3.66 & 14.45 \\
\hline 2007 & 62.0 & 80.87 & 2.65 & 15.21 \\
\hline 2008 & 66.8 & 81.73 & 1.69 & 15.23 \\
\hline 2009 & 71.4 & 79.22 & 1.59 & 18.00 \\
\hline 2010 & 77.9 & 77.92 & 1.47 & 18.81 \\
\hline 2011 & 79.7 & 76.88 & 1.26 & 19.86 \\
\hline 2012 & 84.8 & 72.55 & 0.00 & 24.74 \\
\hline \multicolumn{5}{|c|}{ Source: Original data from http//www.stats.gov.cn. } \\
\hline
\end{tabular}

Source: Original data from http://www.stats.gov.cn.

Obviously, at the present stage landfill is still the main approach. Incineration technology has started to be applied and given more and more attention, but it is still not popularized. In addition, incineration technology has been promoted only in some big cities, but many small- and medium-sized cities have no condition to promote and apply it.

\subsection{Treatment effects and problems}

At present, although the treatment rate of municipal solid waste has reached $85 \%$ or so, about $15 \%$ of the waste is still not effectively treated. Environmental pollution caused by the waste should not be underestimated. More importantly, the treatment rate of municipal solid waste in some small- and medium-sized cities is still far lower than developed big cities, while treatment levels of the waste in urban fringe and suburban region are lower.

Landfill is a lower cost approach, and only because of this reason, at this stage it has popularized and been applied in China's cities. However, landfill will not only take up a lot of land, but also cause secondary pollution. Especially, some small and medium cities mostly adopt the simple landfill or semi-sanitary landfill and thereby secondary pollution is serious, causing serious impact on the life of surrounding residents and agricultural production. In addition, with the increasing waste, landfill site selection becomes more and more difficult, even causing the contradiction between cultivated land and landfill land.

In recent years, incineration technology has been paid more and more attention, while its biggest advantage is less land occupation and has not nearly the secondary pollution. However, compared with the landfill, its processing costs and technical requirements are relatively high (Tsaia et al. 2006). To reduce costs, it is necessary to collect and use heat energy to generate electricity or supply heat, which requires a corresponding technology to improve the efficiency of energy production and use. Obviously, it needs a lot of investment. Therefore, many cities only take simply incineration but not to produce electricity or collect heat at this stage, causing high treatment costs.

\section{RESTRICTING FACTORS}

\subsection{Technique}

Municipal solid waste treatment technologies, including landfill, high-temperature sterilization or microbiologic fermentation into animal feed, aerobic composting, anaerobic digestion into biogas and fertilizer, pyrolysis conversion into organic matter, and incineration and power generation, have their own advantages and disadvantages respectively and are suitable for use in different conditions (Zhang et al. 2010, Dou 2015). Many techniques have been commercially promoted and applied in the cities of developed countries, and played good environmental and economic benefits.

However, the current solid waste treatment technology in China is still far behind the developed countries. On the one hand, basic and key technology innovation is inadequacies, and it is still at the stage of introduction and imitation, which fundamentally restrict the development and application of related technologies. On the other hand, commercial development level in the applied technologies is low, and ordinary enterprises and institutions are not willing or are difficult to conduct the research, development and promotion of corresponding technologies and lack the corresponding talents, too. These are affecting the innovation of solid waste treatment technology in China, thereby affecting the effect and efficiency of municipal solid waste treatment.

\subsection{System}

At present, municipal solid waste treatment in China from the collection and transportation to final processing is dominated by the municipal environmental protection department. Imperfect system results in at least two aspects of problems. On the one hand, as the producer of the waste basically does not assume any responsibility, or charge is not in accordance with the amount of generated waste, it leads to increasing waste generation. On the other hand, because the operating funds in waste treatment come mainly from the fiscal funds, it leads to backward environmental protection facilities including waste collection, 
pretreatment, removal and disposal facilities, directly and indirectly leading to the pollution of the environment.

\subsection{Market}

Successful application of solid waste technology requires a corresponding market to ensure it, including the front-end and back-end markets. For example, aerobic fermentation composting needs the source of raw materials from organic waste as well as the market demand for organic fertilizer and both are indispensable. However, two markets cannot be guaranteed in practice. This is the primary reasons resulting in most of composting plants to stop running in 2012.

In fact, compared with the general market, the front-end supply markets for raw materials and the back-end demand markets for the products from solid waste treatment enterprises have a lot of uncertainty. The supply for raw materials at the front-end depends on waste generation, sorting and recycling, pretreatment and collection from scattered collection points. If there is no corresponding system to make a guarantee, it will result in the uncertainty in supply. At the same time, the users of products from the back-end treatment are small and scattered. For example, the fertilizer from the composting plant needs to be sold to farmers, and the animal feed produced from microbial fermentation of the waste needs to be sold to many breeders and so forth. All seem to have a lot of uncertainty. This is one of the main factors that the solid waste treatment is difficult to achieve the market-oriented operation (He 2014).

\subsection{Policy}

Municipal solid waste treatment has the nature of quasi-public goods, requiring to give appropriate preferential policies of environmental protection enterprises on market access, financing, investment, taxation and subsidy. However, at present because of integration of government administration with enterprise in environmental governance, the government's environmental protection enterprises lack the independence and market operation power, and some preferential policies have not really been implemented. This not only leads to the lack of operating funds for environmental protection enterprises, but also affects the operation power and efficiency of environmental protection enterprise.

\section{COUNTERMEASURES AND PROSPECTS}

\subsection{Countermeasures and policies}

The primary measure to solve practical problems is the reform of the operation and management system, and its core is to implement the management and operation mode of the combination of the government promotion with market orientation. Specifically, it is to realize the separation of the government from the enterprises. The municipal environmental protection department is mainly responsible for the macro guidance and supervision and management, while specific municipal solid waste treatment is achieved by the related environmental protection enterprises in the manner of the market operation. At the same time, the government has to give appropriate assistance and preferential in funds and taxation to ensure environmental protection enterprises to obtain a normal profit.

The second is the establishment of incentive mechanism of both public welfare and social responsibility. Environmental protection has a certain public welfare, but a variety of waste generation is personal behavior. Therefore, to reduce individual waste generation and facilitate subsequent classification processing, the charge system of the waste according to the amount of the waste generated should be implemented to reduce the generation of the waste and prevent littering behavior from the source (Tai et al. 2011). At the same time, environmental protection responsibility of the community should be strengthened, and the government should encourage and guide the community to assist the environmental protection departments to carry out environmental education, management and supervision, too.

The third is to actively promote innovation in environmental protection technology. Important foundation and key environmental protection technology should mainly be promoted by the state, while some application environmental technology innovation should be done by environmental protection enterprises and the state and the government gives appropriate aid. At the same time, the country and the local government should adopt policies and measures to encourage social organizations to carry out the research and development of environmental protection technology to promote the development of new environmental protection industries.

The last is the construction of the laws and regulations and government support system related to the collection, removal and processing of wastes to exactly define the rights, obligations and responsibilities of the individuals, the enterprises, the society and the government from the legal. Especially, the implementation of specific operational mechanism and preferential policies and measures such as the financial subsidies, investment and tax needs the relevant laws and regulations to protect them to ensure the sustainability of this work. 


\subsection{Future prospects}

As the collection, removal and processing of municipal solid waste have the nature of quasipublic goods, so it is necessary under the principle of giving priority of environmental benefit and considering economic benefit to implement publicprivate cooperation participation mode. Environmental benefit priority stresses that the government and environmental protection departments must bear the responsibility of governance of municipal solid waste and the problem can't be solved completely according to the commercialization and market-oriented means, which is a different point from other economic activities. Considering the economic benefit stresses that the concrete municipal solid waste treatment can be entrusted to the environmental protection enterprise through the commercialization and market means to run, while the operational costs are shared by the individuals, the enterprises and the government. The individuals share the costs with garbage fees and the government shares the costs through the appropriate subsidies, tax breaks, investment and other measures, but other costs shall be borne by the enterprises themselves. It can not only arouse the enthusiasm of people's emission cut and the classification and recycling in accordance with the provisions, but also can arouse the enthusiasm of enterprise's technology and management innovation. At the same time, it can alleviate the problems of government turnkey, too.

In practice, China should actively learn the successful experience from foreign countries to implement the classified garbage collection and charging system, and realize as soon as possible the information management of generation, classification, collection, preprocessing and removal of municipal solid waste, and strengthen the supervision, monitoring and management. In the final treatment link, the commercialization and market-oriented operation should be implemented, and the government should encourage individuals and social capitals into the research and development, promotion and application of solid waste treatment technology. The government should still use the proper pricing, subsidies and financing mechanisms and policies to fully mobilize the enthusiasm of the relevant environmental protection enterprises to make the municipal solid waste treatment to really become an emerging environmental protection industry.

\section{CONCLUSIONS}

Municipal solid waste contains large amounts of harmful substances, which will cause serious pollution on the urban environment. However, at this stage China's municipal solid waste has not still realized completely harmless and resource treatment and most of the wastes are treated through a simple or semi-sanitary landfill manner, while incineration is still at the trial and the promotion and application stage. On the whole, the harmless and resource treatment of municipal solid waste is limited by technology, system, market and policy factors. Therefore, it is necessary through the technology, system and management innovation to address these problems.

\section{REFERENCES}

[1] Dou, X.S., 2013. Low carbon economy development: China's pattern and policy selection. Energy Policy 63:1013-1020.

[2] Dou, X.S., 2015. Food waste generation and its recycling recovery: China's governance mode and its assessment. Fresenius Environmental Bulletin 24: xxx-xxx. (in press)

[3] He, Y.T. 2014. Treatment of municipal solid wastes: foreign experience and China's reference and associated policies. International Journal of Academic Research in Business and Social Sciences 4: 47-56.

[4] Tai, J. et al. 2011. Municipal solid waste source-separated collection in China: a comparative analysis. Waste Management 31: 1673-1682.

[5] Tian, H.H. et al. 2013. Atmospheric pollution problems and control proposals associated with solid waste management in China: a review. Journal of Hazardous Materials 252-253: 142- 154 .

[6] Tsaia, W.T. \& Chou, Y.H. 2006. An overview of renewable energy utilization from municipal solid waste (MSW) incineration in Taiwan. Renewable and Sustainable Energy Reviews 10: 491-502.

[7] Wei, Y.S. et al. 2000. Composting and compost application in China. Resources, Conservation and Recycling 30: 277300.

[8] Zhang, D.Q., Tan, S.K. \& Gersberg, R.M. 2010. Municipal solid waste management in China: status, problems and challenges. Journal of Environmental Management 91: 1623-1633.

[9] Zhou, H. et al. 2014. An overview of characteristics of municipal solid waste fuel in China: physical, chemical composition and heating value. Renewable and Sustainable Energy Reviews 36: 107-122. 